\title{
A PUNCH CARD FOR DECAY STUDIES ${ }^{1}$ BY W. B. G. DENYER ${ }^{2}$ and D. E. ETHERIDGE ${ }^{3}$

\author{
$A B S T R A C T$
}

A tree record for use in decay studies incorporating a Reinecke form on a panch card is described. This card is currently being used in decay studies the Prairie Provinces.

In decay studies conducted in the Prairie Provinces, a Reinecke form *, or a tabular field form have been used to record data of individual trees. These data, after volumes had been calculated, were transferred to punch cards to facilitate analysis. A new form has been devised to combine a field sheet with a punch card.

At present this card is being used in decay studies by the Forest Pathology Laboratories at Saskatoon and Calgary. The adoption of a standard form for all Canadian decay studies would encourage and facilitate the interchange of data between regions.

The face of the card (Fig. 1) contains the usual information on location, diameter, age, increment, computed volume, and deduction. Space is provided for notes on as many as four different kinds of decay or separate infections that may occur in a single tree. The tree depicted on the card (Fig. 1) contained three different decays. In this section, "field identification" is completed in the field where possible, but "name" is entered only after positive identification from cultures, sporophores, comparison with type decay specimens, or a combination of these methods. This provides a useful check on the accuracy of field identification. "Culture at" refers to the height above ground at which a wood sample was taken for culturing. Similarly "specimen at" is the height at which a sample of the most advanced stage of decay was taken. The latter is not usually cultured, but is compared with type decay specimens as an aid in identification. "Volume" refers to decay volume.

Sections of holes bordering the card are allotted to age, diameter, site, crown class, plot number, trunk, and root rots, so that the data may be sorted for any one or a combination of these factors. Fig. 3 shows the value or identity assigned to individual holes. By utilizing twenty-year age classes, the card provides for a range of age from 0 to 220 years and two-inch diameter classes provide a range of diameter from 2.6 to 34.5 inches. The class interval for age or diameter may be changed to suit individual studies. Under root and trunk rots, individual holes are assigned to specific decay-causing fungi. In the example (Fig. 1) hole 1, Fomes pini, and hole 2, Stereum sanguinolentum, are punched under trunk rots, and hole 2, Polyporus circinatus, under root rots. Plot number is punched to allow quick resorting of cards into plots. In Fig. 1 the plot number is 369. This is entered by punching: holes 7 plus 2 under

\footnotetext{
${ }^{1}$ Contribution No. 310 from the Forest Biology Division, Science Service, Department of Agriculture, Ottawa, Canada.

Forest Pathology Laboratory, Saskatoon, Sask.

${ }^{\mathrm{a}}$ Forest Pathology Laboratory, Calgary, Alta.

- U.S.D.A. Form 558-A (see: Chapman, H. H. and W. H. Myer. Forest Mensuration. McGraw Hill Book Company, Inc. pp. 100-103. 1949.), or Canadian adaptations Forms 5B-239 and SB-246.
} 


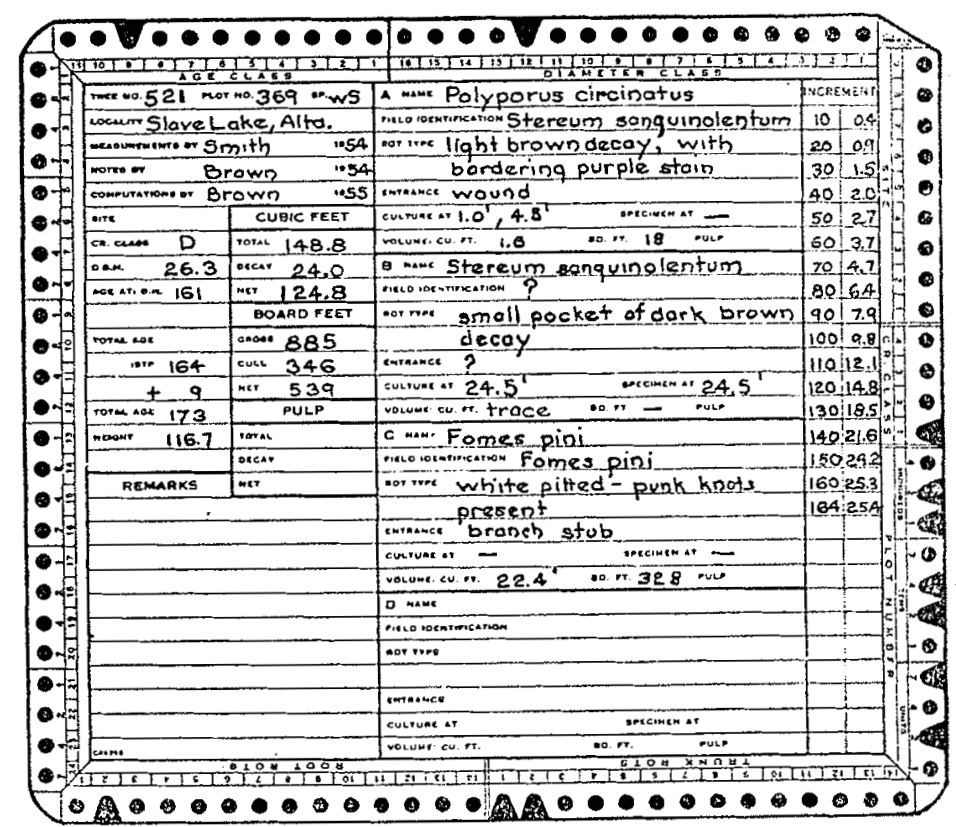

Figure 1. Face of punch card with data for a sample tree. $X 1 / 2$.

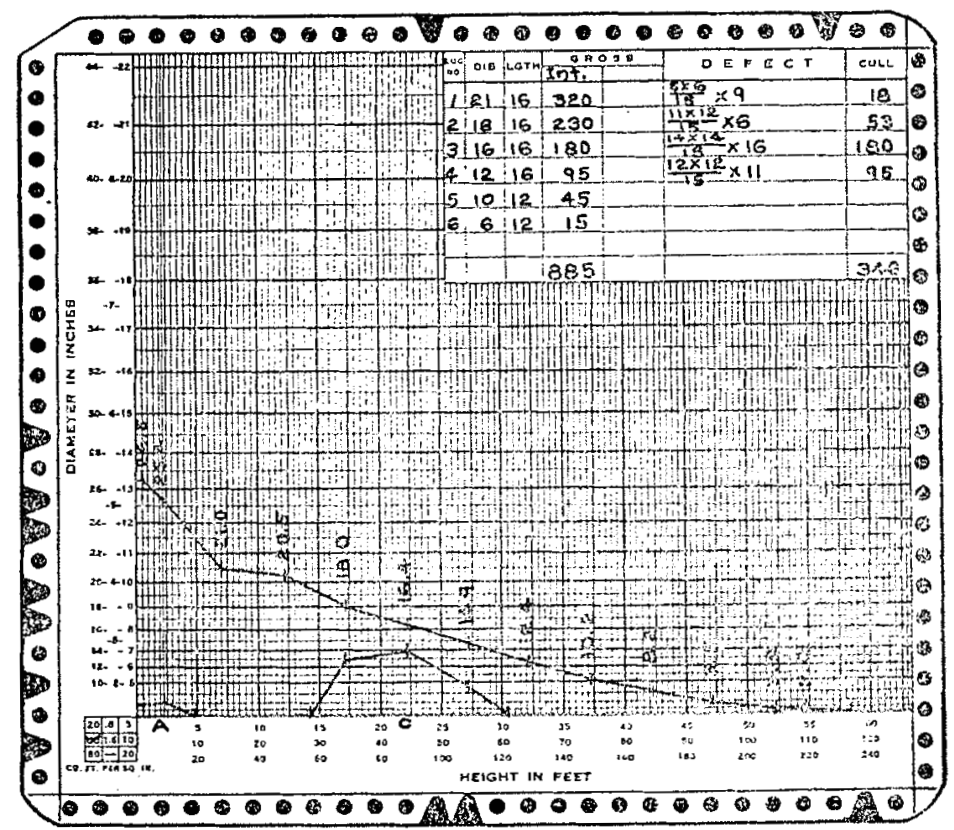

Figure 2. Reverse side of punch card showing logarithmic tree form with data for a sample tree. $X 1 / 2$. 


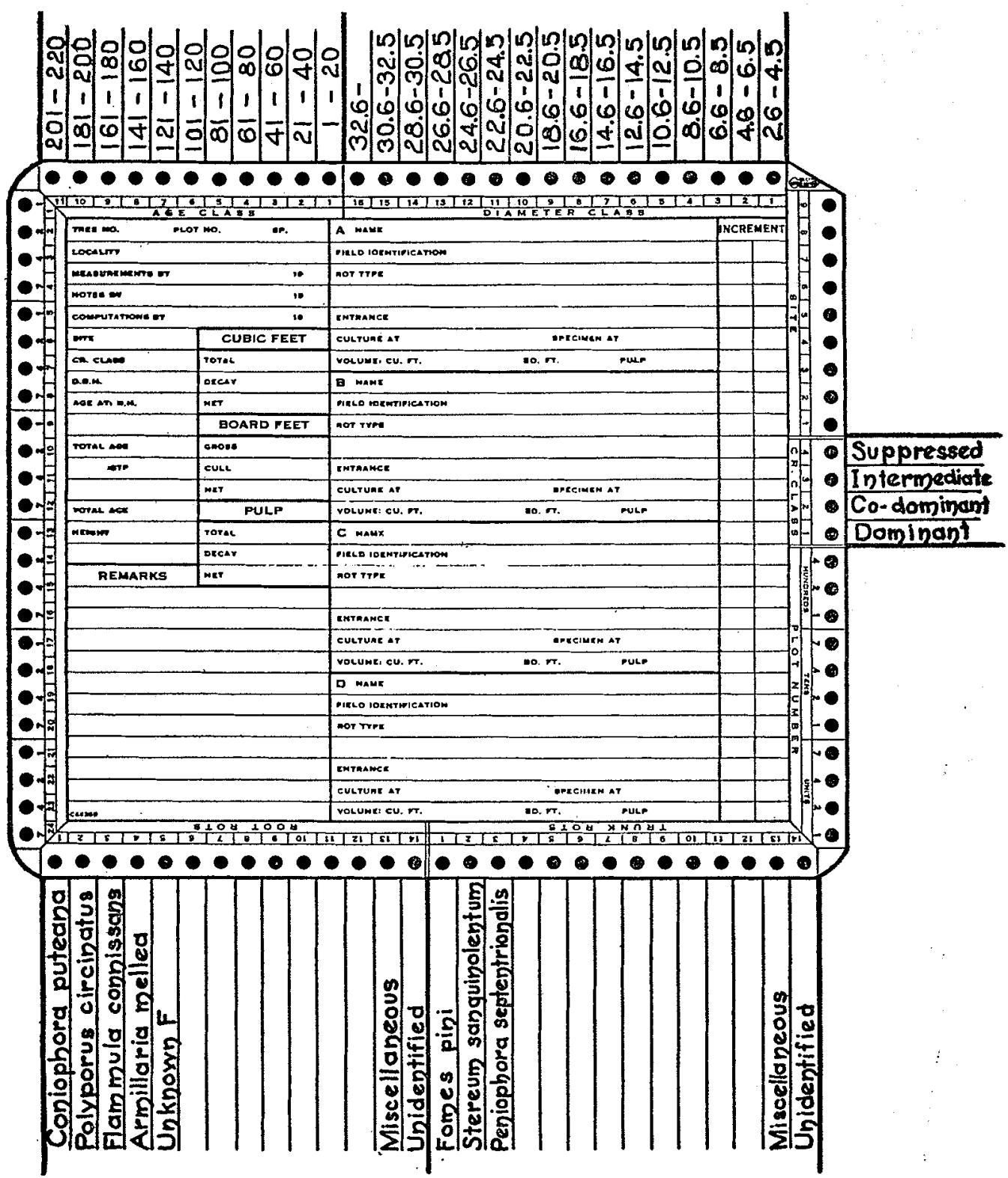

Figure 3. Master card showing designation or value of marginal holes. $\mathrm{X} 3 / 2$. 
"units", 4 plus 2 under "tens", and 2 plus 1 under "hundreds". The holes on the left border of the card are not assigned and may be used for additional factors that may arise in a particular study. They are arranged in groups of four holes numbered $7,4,2,1$. The method of punching them is the same as described for plot number. A maximum of 14 values may be assigned to each group of four holes.

The reverse side of the card (Fig. 2) is copied without modification from the lower left portion of Form SB-246. This part provides for plotting diameters up to 44 inches and heights to over 200 feet, adequate for all ordinary measurements except in British Columbia. In Fig. 2 a sample tree with two decay infections ( $\mathrm{A}$ and $\mathrm{C}$ on the front of the card, the volume of $\mathrm{B}$ is negligible and not plotted) is plotted in the logarithmic tree form. Log scale in board feet and deductions for defect are entered in the upper right section. Two columns under "gross" allow the use of two log rules.

As far as practicable the data are entered directly on the card in the field. The determination of volumes by a planimeter and the punching of cards is done in the office. Punching the cards is facilitated by the use of a master card (Fig. 3). This consists of a sample punch card mounted on a sheet of bristol board on which is shown the value or designation of the marginal holes. During the punching operation the master card is consulted to ascertain the holes to be punched.

The time required to sort tree data in decay studies by age, diameter, site class, and for presence of decay fungi, may be greatly reduced by using a punch card. A logarithmic tree record form is widely used in Canada in decay studies because it provides a record in which tree volumes may be easily obtained to a variety of standards, i.e., total volumes or merchantable volumes to various limits. The tree form described combines the advantages of a punch card with a logarithmic tree form. 